\title{
Title: Sport Sponsorship Alliances: Relationship Management for Shared Value
}

Ashlee Morgan, Daryl Adair, Tracy Taylor and Antoine Hermens

University of Technology, Sydney

UTS Business School

PO Box 123, Broadway, NSW 2007, Australia

\section{Corresponding Author:}

Ashlee Morgan

$\underline{\text { Ashlee.morgan@uts.edu.au }}$

\section{Authors' Biographies:}

Ashlee Morgan is an academic in the Management Discipline Group at the UTS Business School. Ashlee has recently completed her PhD in sport management, examining the governance of corporate sport sponsorship. Her research interests are in strategic alliances, business-tobusiness relationships and sport sponsorship.

Daryl Adair is Associate Professor in the Management Discipline Group at the UTS Business School. He is on the editorial board of several academic sport journals. His most recent book (with Stephen Frawley) is the edited collection Managing the Olympics (Palgrave, 2013).

Tracy Taylor is a Professor of Sport Management and Deputy Dean at the UTS Business School. Tracy is editor of Sport Management Review and has published widely in sport and leisure management journals. Her research includes human resource management and managing people in sport organisations.

Antoine Hermens is the Head of the Management Discipline Group at the UTS Business School. He is also the Director of the Global Executive MBA program at UTS. Antoine spent the first 25 years of his career as a manager and executive in companies in the international automotive industry sector. His research lies within the areas of strategy and alliance management. 


\begin{abstract}
Purpose

Using a case study of an international sport event, this paper examines the inter-organisational relationship between a sport event property and its corporate sponsors.

Methodology

Interviews were conducted with personnel from the National Sport Organisation (NSO) responsible for the delivery of this major event, and from four of its corporate sponsorship partners.
\end{abstract}

Findings

The findings indicated that both formal and informal governance were critical to the relationships underpinning these sponsorship alliances. From a dyadic perspective, it was found that the satisfaction of sponsorship partners had two key elements: tangible commercial benefits from the sponsor-sponsee alliance, and the less tangible but none the less valuable relationship support within the partnership. In short, partner satisfaction and alliance stability stemmed from relational constructs and the balance of formal governance mechanisms.

Value

This paper explores the variables that generate value and maintain alliance stability for improved sponsorship governance. These findings, while focused on a single case study, have implications for research in the field of sponsorship and to the area of business-to-business relationships more broadly.

Key words: sport events; sport sponsorship; inter-organisational relationships; sponsorship governance; value

Article Classification: Research paper 


\section{Introduction}

In the last three decades the sport industry has experienced phenomenal growth, with major sport events a feature of the global business landscape. Indeed, professional sport organisations and their leagues or tournaments could not function at current capacity without the revenue generated through commercial activity, such as broadcasting, ticket sales and sponsorship income. Among these revenue streams, the focus of the present study is with sponsorship, which has assumed an increasingly significant role in financing and promoting

professional sport. For example, the International Event Group recently reported that in 2012 annual sport sponsorship expenditure reached \$13.01billion in North America alone (International Event Group, 2013). However, while this paper acknowledges the financial importance of sponsorship, it has a more specific purpose - to examine the management of stakeholder relationships within a sponsorship alliance.

The escalation of sport sponsorship over the last thirty years has triggered research into several key areas, such as the objectives and rationale for sponsorship investment, sponsorship evaluation, and the management of sponsorship relationships (Cornwell and Maignan, 1998; Walliser, 2003). It has been argued that the strength of the inter-organisational relationship between the sport property and corporate sponsor is pivotal for partner satisfaction and longevity of association (Amis, Slack, and Berrett, 1999; Farrelly, Quester and Burton, 2006). Despite the noted importance of the relationship between sponsor and sport property in much of the sponsorship literature, the internal dynamics of sponsorship alliances and the creation of value within these partnerships is surprisingly under-developed. In particular, there has been a lack of empirical research in which stakeholder relationships are investigated by qualitative means. This 
methodology gives voice to sponsors and their sponsee, providing the prospect of deep insights into the governance of inter-organisational relationships, complementing quantitative analyses.

In order to explore and better understand the business-to-business (B2B) relationship between a sport property and corporate sponsor, this paper used a case study approach to examine sport event sponsorship as an inter-organisational alliance between two distinct types of entities. The aim was to gain a better understanding of B2B relationships underlying a sponsorship alliance. Using an exploratory approach, the study investigated the interplay between sponsorship partners (sponsors and sponsee) with the goal of highlighting the complex dynamics of inter-organisational relationships.

\section{Background}

Contemporary sponsorship has recently been recognised as a 'co-marketing alliance' or 'strategic partnership' between two organisations (Farrelly, 2010; Renard and Sitz, 2011). It has been argued that the most successful sport sponsorships are based on a productive relationship between the sport property and sponsor organisations (Nufer and Bühler, 2010), characterised by ongoing dyadic interaction and cooperation (Dolphin, 2003). Sponsorship now represents a significant component of integrated marketing strategies and a substantial proportion of the marketing budget of organisations investing in large-scale sponsorship properties. Thus there is demand by sponsoring organisations for a discernible return on their investment. Due to increasing managerial pressure for accountability of this expenditure, contemporary sponsorship increasingly requires strategic planning, implementation and evaluation (Choi, Stotlar, and Park, 2006; Stotlar, 2004).

A wide variety of sponsor-sponsee configurations exist in contemporary sport. The sponsor can range from corporate businesses, government agencies and not-for-profit 
organisations. The sponsee or sport property can also range from an individual athlete; a local, regional or national sport organisation; an international sport federation; a sport event, tournament or seasonal competition; or a sport club (of any size). Furthermore, the broadcast of sport can be sponsored and sport stadiums allow naming rights sponsors. Clearly, therefore, sponsorship is now an endemic feature of professional sport.

As the sport sponsorship industry has grown significantly over the past three decades, the size of sponsor investments, specifically in large-scale global events, has also escalated. For example, during the most recent Olympic Games quadrennium (2009-2012), The Olympic Partners (TOP) programme received US\$957 million from 11 sponsoring organisations (International Olympic Committee [IOC], 2012). This is a significant increase from the US\$579 received during the 1997-2000 quadrennium from the same number of partners (IOC, 2012).

Corporations invest sponsorship capital and resources to pursue an array of business objectives, marketing strategies, and competitive strategies. Sponsorship in global sport provides organisations with opportunities for international marketing and brand leverage. Thus sport has the capacity to reach beyond national boundaries and connect directly with diverse markets; this makes it enticing to sponsors who are seeking international exposure (Lagae, 2005).

\section{Literature Review}

\section{Sponsorship Research and Sport}

Sport sponsorship is a sophisticated and versatile marketing tool that provides great potential for commercial leverage. Sponsorship provides businesses with nimble promotional opportunities, such as: cutting through the clutter of traditional advertising (Duncan, 2002); communicating directly with various stakeholders (Lagae, 2005); and differentiating one's brand 
within the competitive market (Cornwell, Roy, and Steinard, 2001; Meenaghan and Shipley, 1999).

Although research to date has predominantly focused on the objectives of the sponsor within the sponsorship arrangement (Apostolopoulou and Papadimitriou 2004; Berkes, Nyerges, and Vaczi, 2009; Hartland, Skinner, and Griffiths, 2005), there is also undoubtedly vast benefit for the sponsored sport property, such as market exposure and brand-related benefits (Henseler, Wilson, and de Vreede, 2009).

Establishing and maintaining cooperative arrangements between sport property and corporate sponsor are important for longevity of association (Amis et al., 1999; Meenaghan, 1998). Early work in this area discussed sponsorship as a "symbiotic relationship with a transference of inherent values from the activity to the sponsor" (Meenaghan and Shipley, 1999, p. 335). In addition to this symbiotic alignment, the concept of co-branding between sponsor and sport property has also been suggested (Motion, Leitch, and Brodie, 2003). This notion of cobranding is contingent upon the belief that sponsorship success is influenced by the brand strength of both the sponsor and sport organisation (Kahuni, Rowley, and Binsardi, 2009; Urriolagoitia and Planellas, 2007; Westberg, Stavros, and Wilson, 2011). Indeed, it is now recognised that for sponsorship to function effectively, a sponsor and sport property need to have a productive B2B relationship (Davies, Daellenbach, and Ashill, 2008). Crucially, therefore, scholars are now referring to sponsorship as a co-marketing alliance (Farrelly, 2010; Farrelly and Quester, 2005b; Renard and Sitz, 2011).

However, as Farrelly and colleagues have noted: "there is very little evidence of research examining how key business-to-business relationships...can impact sponsorship effectiveness" (Farrelly, Quester, and Mavondo, 2003, p. 128). In the ensuing period there has been limited 
empirical response (Farrelly et al., 2006). Indeed, the majority of research in this area remains either theoretical or anecdotal. Researchers have recognised that further inquiry is needed into: internal communication processes that precede decision-making (Farrelly, Quester and Burton, 1997), antecedents to sponsorship outcomes (Alexandris, Tsaousi and James, 2007), and motives or processes that underpin inter-organisational relationships (Farrelly et al., 2006). The present study was undertaken to gain a better understanding of sponsor-sponsee relationships, presupposing that such knowledge is likely to improve the management of these interorganisational arrangements, and at its optimum even assist value co-creation.

\section{The Relationship Dimension}

Inter-organisational relationship management within a sport sponsorship arrangement has been examined using a relationship marketing perspective (Farrelly et al., 2003; Ryan and Fahy, 2003). In a theoretical analysis of sponsorship arrangements, Renard and Sitz (2011) emphasised the importance of a strong B2B relationship between sponsor and sport property for deriving brand-related value from the partnership. Notably, Kahuni et al. (2009) found that productive sponsor-sport property relationships minimise the impact of degenerative episodes that may arise within the sport context. Thus, the governance of these inter-organisational relationships is pivotal to the success and sustainability of the sponsorship arrangement (Alexandris et al., 2007; Farrelly and Quester, 2005a; Farrelly et al., 2006). However, as highlighted by Cousens, Babiak and Bradish (2006), despite the increased discourse on B2B coordination and relationship management in a sponsorship context, there is still a significant amount that is unknown about relationship dynamics within a sponsorship alliance. This is all the more important in terms of relationship management because a sponsor and sport property may either have or be seeking a long-term partnership (Chadwick and Thwaites, 2005; Farrelly, Quester, and Clulow, 2008). 


\section{Alliances}

At its most rudimentary level, strategic alliances are relationships between two or more organisations that are formed to satisfy individual and common objectives (Hanson et al., 2005; Mandal, Love, and Irani, 2003). Inter-organisational alliances are fundamentally a vehicle to enhance business performance by providing complementary capabilities that would ordinarily exceed the capacities of a singular firm (Dyer and Singh, 1998; Ireland, Hitt, and Vaidyanath, 2002). Typically, the underlying rationale of inter-organisational alliance formation is the strategic generation and sustainability of competitive advantage (Bell, den Ouden, and Ziggers, 2006; Kale and Singh, 2007).

Farrelly and Quester (2005b) have explored strategic compatibility, goal congruence, commitment, trust and satisfaction; they concluded that sport sponsorship relationships do have the potential to operate as alliances, providing a strategic platform with the goal of creating mutual satisfaction. Indeed, Farrelly (2010, p. 332) has contended that great value would be added to the sponsorship area if future research is conducted "thorough examination of sponsorproperty partnerships that have cultivated strategic collaboration with attention given to the planning process, formal and informal communications between partners and the nature of objectives set down for the relationship".

Taking Farrelly's lead, the present study explored the governance processes and mechanisms that facilitate the generation of value within the sport sponsorship alliance. The complexities of the B2B relationship and areas of governance that influence partner perceptions of alliance performance were located within the interplay between sponsorship partners. The 
research explored how these relationships influenced perceptions of value and performance within the sponsorship arrangement.

The primary research objective was: To explore the internal dynamics of the interorganisational alliance that is formed between sport organisation and corporate sponsor. The study was designed to provide insights into the governance of sponsorship from both sides of the inter-organisational alliance, with the purpose of understanding of how value is created and relationships managed therein.

\section{Method}

The study was embedded within an interpretative paradigm that allowed a qualitative examination of the relationship between organisations in a dyadic sponsorship alliance, providing "a 'practical understanding' of meanings and actions" (Miles and Huberman, 1994, p. 8). As sponsorship has been conceptualised in this study as a dyadic partnering of two entities, the sport property and sponsor organisation(s), it was imperative to gather empirical insights from both sides of the dyad. To pursue an inquiry of this kind, a case study of a major sport event and four of its corporate sponsor organisations was conceived. Due to commercial in confidence restrictions, identity of the sponsee [an Australian national sport organisation (NSO)], its event [major international event (MIE)], and its sponsors must remain confidential. The alliances between the NSO and four of the MIE's corporate sponsors were explored, albeit without identifying any of the organisations by name.

The NSO is the national governing body for its sport at all levels within Australia, from grassroots participation to the organisation of an international competition, the largest of these being the MIE studied. The MIE attracts vast international media, business and public attention. For example, in 2012 it had well over 300,000 on-site attendees, was broadcast to more than 200 
countries and had more than 40 million website visits (NSO, 2012). This internationally recognised sport event is used to investigate the complexities of large-scale sponsorship arrangements.

The four case sponsor organisations were labelled as A, B, C and D for reasons of anonymity and confidentiality. They are all commercial organisations, three of which are multinational corporations, while the fourth is a national business.

To explore the perceptions of those directly involved in sponsorship governance within both the NSO and its corporate sponsor organisations, the main data collection method was semistructured interviews. Respondents were selected according to their immediate involvement with sponsorship of the MIE within their respective organisation; using the strategy of purposive sampling (Denzin and Lincoln, 2005). The interviewees within the four sponsor organisations were directly responsible for the management of their organisation's MIE sponsorship. Within the NSO, interviews were conducted with the entire sponsorship branch of its Commercial Sector. A total of 19 interviews were conducted with 14 participants across the five organisations. The interviews lasted between 30 and 90 minutes.

A document analysis was also employed to provide background information and to detail broader organisational structures and processes. Official documents related to the marketing and sponsorship of the MIE and NSO were examined. Information was sourced from annual reports, strategic planning documents, marketing documents, organisational policies, press releases and website documentation, dating back to 1980. The data sourced from these documents provided historic insight into the NSO's growth and development, formal structures, strategic direction and organisational priorities. This allowed for retrospective analysis, which provided background information prior to interviewing key informants. 
The data, from both interviews and documents, were manually coded and analysed. In line with the interpretive paradigm that underpinned this research, themes were not predefined, but rather emerged during the data collection and analysis process. Data analysis followed an iterative path from the initial data collection phase to the completion of the research. All interviews were electronically recorded, with participant consent.

Creating codes or categories of qualitative data facilitates the creation of a conceptual scheme specifically suitable to that data set (Basit, 2003). In this study, open coding was conducted first; that involved assigning open codes to chunks of text. Axial coding followed, refining the initial open codes; more specific labels could now be allocated to the text. At this stage, codes were split into subcategories, identifying relationships both between codes and the overall combination of codes (Neuman, 2003). In an effort to systematically arrange the large quantity of interview data, various matrix configurations and tables were established. In scholarship of this nature, it is the researcher's decision how to code data, and which sections to pull out as most relevant to tell the analytic story of the case study.

\section{Findings and Discussion}

Through the coding process and data analysis described previously, a number of constituents were found to have direct influence on relationship management and perceptions of value within the inter-organisational arrangements.

The NSO and sponsor interviewees recognised significant value stemming from their respective sponsorship relationships. When the sponsors were asked what value this event presented to their organisation, a common reason for continuation of the sponsorship was the "premiumness" of the event. It was acknowledged that if the event lost its premium edge, or if 
the direction and marketing of the event changed, it would impact directly on renewal decisions. The sponsors related this to the international prestige of the MIE and its strategic value for their global strategy and brand marketing. The sponsors also emphasised competitive advantage from their association with the MIE in terms of the tangibles and brand-related intangibles the sponsorship offers in global and local markets. Especially within competitive local industries,

sponsors acknowledged that their MIE sponsorship provided significant advantage.

It was revealed that the value of sponsorship for the NSO went well beyond the financial investment of sponsors. The reputation of sponsors within the marketplace was also of critical concern. The sport property was fully cognisant of the importance of brand fit, image and transfer and compatibility with their sponsors. As the NSO's Head of Sponsorship summed up, "who you partner with tells you everything about your own business". There was shared sentiment among all interviewees that sponsorship is a co-marketing initiative and that the brand of each partner is pivotal to market performance.

The NSO and sponsors identified a number of areas that impacted on value within their sponsorship relationships. The following discussion outlines four areas found to have significant influence on the internal dynamics of the inter-organisational alliances investigated: relational value, staff turnover, formal governance and decision-making.

\section{Relational Value}

Favourable and trustworthy relationships are assumed to minimise the barriers that arise in the ongoing management of sponsorship alliances for both parties. In the present study, the sport property recognised that strong inter-personal relationships were helpful during difficult negotiations, complex discussions, or even when rejecting sponsors' requests (such as extra space for logos). Confidence and trust in dealing with partners was deemed to be a cornerstone 
of effective management of sponsorship portfolios. As the NSO's Commercial Director stated, "That is what drives sponsorships, the relationship you have with people, not with businesses."

Importantly, it was not only formal relationships that provided a basis for confidence and trust; informal inter-personal relationships were also highly valued by the interviewees. Sponsors perceived relationships as integral during negotiation and renewal periods, while both the sport property and sponsors indicated that strong inter-personal relationships actually make it easier to manage the formalities of a business arrangement. Sponsor A noted that it is very important on a day-to-day basis to have a good relationship, but also during contract negotiation, "the year we renew the contract the relationship is really a key point". Sponsor C had a similar view, indicating that good relationships help them to introduce new elements into a contract.

A significant driver of alliance value for the sponsors was found to be "open and honest communication" (Sponsor B). These characteristics were not only crucial for sponsors to feel satisfied, they also asserted that they limited and curtailed inter-partner hostility. For example, Sponsor B admitted, "It might not be as easy to hear upfront but ... but now we haven't wasted three weeks talking about an issue before we got the truth."

The interviewees conceded that when communication between themselves and the other party have been poor, relationships have been much more likely to be strained. For example, the NSO sometimes experienced internal communication breakdowns, which affected flow of information and response time with partner organisations. As Sponsor B noted: “... an area that [the NSO] probably falls down in is their internal communication. So their marketing team, their sponsorship team, their operations team often don't seem to talk as much as they should, or don't seem to know what's happening." There were also some misgivings about depth of information provided by the NSO. Three of the sponsors indicated that they would like to know more about 
the strategic intent and market orientation of the NSO. Sponsor C discussed this in bilateral terms, emphasising that the NSO needed to appreciate that strategic intent and partnership congruence are vital to sponsors: "it really complicates things when we are trying to get things across the line and they don't understand why”.

The general consensus among interviewees was that the development of dyadic commitment and trust was imperative for their partnership to succeed. This was reiterated throughout the interviews, as the NSO's Head of Sponsorship stated, “There's one thing in my view that you can't buy in business and that is trust". However, as discussed below, there are risks associated with alliances that are governed heavily on inter-personal trust and commitment. If significant staff turnover occurs in a relatively brief period, the salience of personal contacts may break down and the degree of shared corporate knowledge may diminish.

\section{Staff Turnover}

All of the sponsors interviewed referred to the impact of personnel change on their partner relationships. They noted that this impacted on the governance of the relationship, as many discussions and agreements take place on an inter-personal basis and are not necessarily documented in the formal contract. The high rate of staff turnover within both the NSO and sponsor organisations was commented on by interviewees from both sides of the alliance. The NSO in particular underwent significant personnel change in the sponsorship area during 201112. There was consensus among the NSO and sponsors that any staff change impacts relationships and sponsorship governance.

Staff turnover can have a degenerative impact on a partnership in terms of knowledge transfer, personal understandings of one another's business and appreciation of stakeholder expectations. Interviewees emphasised that inter-organisational understanding and knowledge 
were lost with the change of staff, which affected ongoing relationship building and consistency. They noted that the impact of this could be managed more effectively if collaborative governance processes, partner objectives and expectations were better documented. Sponsors asserted that handover processes during staff turnover could be improved to minimise loss of know-how and social capital.

Temporal power issues were found following staff turnover and during the induction of new staff. These time-related concerns stemmed from duration individuals had been involved in the management of the sponsorship arrangement. As one of the NSO's Client Service Managers (who was relatively new to the position) noted, "I've had to suck it up a bit last year because they would be telling me how it's done ... you do have those power struggles on a few things more when you're changing things". When these inter-personal power concerns arose during the interviews, the discussion was underpinned by negative and contentious tones. As another Client Service Manager stated, "If I had a dollar for every time I hear "this is how we do it" or "this is how we did it last year". These power-based hostilities may be detrimental to inter-personal relationships and ultimately the stability of alliances.

For all the sponsors, the personal relationships with the NSO's Client Service Managers were pivotal to successful sponsorship, as they are "the one who's going make and approve everything" (Sponsor A). Thus, when inter-personal relationships break down it has a negative impact on the sponsors' perceptions of operational efficiency and satisfaction. However, not all staff turnover was seen as negative. All four sponsors interviewed discussed the positive impact that recent NSO staff changes have had on their inter-personal and B2B relationships. In the past, inter-organisational relationships were strained due to personal differences between the individuals responsible for the sponsorship management within both the NSO and the sponsor 
organisations. As one sponsor commented, "They [the NSO] are working with you now rather than dictating to you" (Sponsor D). It was acknowledged that it takes time for new staff to form relationships with sponsorship partners and "the more time you spend with someone the more you understand how they work, what their personality is" (Sponsor C). Previous studies have found that the regularity and productivity of social exchange occurrences are closely linked to the longevity of sponsorship dyads (Olkkonen, Tikkanen, and Alajoutsijarvi, 2000).

The importance of a good personality fit within sponsorship governance was highlighted by the NSO's commercial management team. In relation to staff turnover, top-tier sponsorship management discussed the importance of an effective relationship and a suitable match between their Client Service Managers and their portfolio of sponsors. The NSO Head of Sponsorship asserted that "in this role there is a lot of customer facing time that the traits and behaviours are the first things I look for in people". As an example, the NSO engaged with sponsors during their recent recruitment process, which was received positively by all of the sponsor interviewees. This example highlights the importance of ensuring that recruitment and selection are strategically aligned with both internal and external managerial needs.

\section{Formal Governance}

The degree to which governance is dependent on formal control mechanisms and contracts can impact the development of partner trust and relational strength. While formal control mechanisms are important in sponsorship governance, the results of this study indicate that formalisation and dependency on formal mechanisms can hinder the sponsors' perceptions of trust and commitment within the sponsorship alliance. 
An interesting finding was the disparity in opinions regarding the importance of formal contracts during ongoing sponsorship management. The majority of the NSO interviewees perceived regular referral to the contract as pivotal during sponsorship governance. The NSO emphasised the importance of tight contractual control and ensuring sponsorship is governed in close conformity to these documents. All the sponsors recognised the importance of having a clear and unambiguous contract; however, they did not believe it should be regularly referred to during sponsorship governance. In fact, the heavy reliance of the NSO on contractual stipulations was revealed to be a significant cause of tension for the sponsors.

The sponsor interviews revealed that from their perspective, the formal contract establishes the partnership; subsequently, importance should shift to the relationship development between organisations. The value of relationship development post contract exchange - or informal alliance elements - is supported by strategic alliance literature (Das and Teng, 2001; Dyer and Singh, 1998). In this study the sponsors indicated that the formal contracts were too restricting on the dynamic nature of business, marketing and organisational change. The stringent approach of the NSO in terms of the contract was discussed by Sponsor A: "if you only stick to the contract that will be quite limited".

Furthermore, the NSO was very cautious not to provide too much benefit outside of what was stated in the established contract. By contrast, the sponsors felt that the contract was only the foundation of the sponsorship and presented the minimum value sought. Contractually tight arrangements therefore encompass both benefits and disadvantages. The presence of formal arrangements reduces the degree of risk, which is advantageous in terms of the transparency of duration, expectations and requirements of partners. A major problem resulting from the NSO's rigid approach to sponsorship governance is the inhibitive effect it had on the dynamic nature of 
the sponsor businesses, especially in regards to the introduction of new products or brand changes.

In terms of other formal governance mechanisms, interviewees confirmed that objectives are spoken about with their sponsorship partners, however nothing about this is formally documented. Interviewees from both the NSO and the sponsors indicated that whilst their sponsorship contracts delineate the scope of sponsorship benefits and obligations, this did not specify either parties' strategic objectives. Despite the regular communication between sport property and sponsor, in this case study there was little evidence of regular strategic collaboration in terms of developing common goals and planning sponsorship activations. Yet the sponsors indicated that improved strategic collaboration and cooperation would strengthen their relations with the NSO. As Sponsor B noted, "I think it's probably a conversation that is worth having". There is capacity to significantly improve strategic partnering. The autonomous governance of sponsorship limits the cooperative activities and desire for collaboration within the sponsorship network.

\section{Decision-Making}

While organisational idiosyncrasies were identified, decision-making processes generally followed a similar progression within each of the interviewed sponsor organisations. This was recognised by the sponsor interviewees as a push up approach. It is evident that operational control of sponsorship activation, associated brand marketing and advertising are a function of the local team, however the final renewal decision is made by top tier management, even when they are operating from overseas headquarters.

Whilst sponsorship was clearly a strategic investment for all the interviewed sponsors, the decision-making power of CEOs or top tier management preference was still significant. As 
one sponsor stated, "as long as there will be a person at the top level, at the head office who likes the [the sport], it will keep going". This comment raises questions regarding sponsorship evaluation and strategic assessment. The personal interest of a CEO or senior management has previously been related to initial sponsorship investment and intent to renew (Amis et al., 1999). Although sponsorship has largely evolved into a strategic marketing tool, it is evident that the personal preferences and interests of CEOs and senior managers still influence sponsorship decision-making.

Whilst the specific antecedents to sponsorship renewal were not detailed by the interviewees due to commercial sensitivities, general considerations were discussed. It was found that during the initial stages of evaluation within the respective sponsor organisations, two core elements are considered: tangible benefits received (e.g. product sales, media coverage, corporate hospitality opportunities), and support provided by the NSO to achieve desired results. Importantly, this second component includes the personal relationships between the organisations and the efficiency of operations within the NSO. Typically, the sponsorship is then reviewed in light of the broader organisational brand strategy, other marketing mechanisms and other sponsored properties. Regardless of the success of sponsorship activity, if it was not aligned to the brand strategy, then it would not be renewed. The strategic brand compatibility between the sport property and corporate sponsor was noted as playing a critical role in decisionmaking.

The number one incentive for sponsors was economic benefit. However, the interorganisational relationship played a crucial role in partner satisfaction and cooperation, which also ultimately influenced renewal decisions. It was noted by both the sport property and sponsors that trustworthy relationships were instrumental in determining perceptions of value 
and inter-organisational support. As the NSO Commercial Director stated, “don't underestimate the power of a good relationship".

Sponsors acknowledged that their outcome focus is high, thus if the NSO puts up barriers or under-delivered then that would impact renewal decisions. These barriers can, however, be mitigated by good relational management. As Sponsor B stated, "if we are having to expend a lot of time and resource and money to get to that result because of barriers that [the NSO] are putting up, that's got to come into the decision as well". So while the personal relationship is not the only driver of renewal or termination, it clearly has influence on decisions. As one sponsor suggested that an important question during renewal periods is "did we get the support we wanted?" (Sponsor D).

The interview data has shown that the formal and informal elements of governance are intertwined. Business outcomes are important for all parties; however, if this is not supported by efficient, productive relationships, the sponsorship will not succeed.

\section{Conclusion}

This research set out to achieve a greater understanding of the dynamics of $\mathrm{B} 2 \mathrm{~B}$ sponsorship relationships. In doing so, it makes a number of contributions to the body of knowledge concerning sport and event sponsorship. It provides insight from both sides of the sponsorship alliance, addressing the calls from scholars for further dyadic sponsorship research (Farrelly et al., 2003; Olkkonen \& Tuominen, 2008). Moreover, it explores relational dynamics within sponsorship alliances, which similarly has been called for (Cornwell, 2008; Farrelly, 2010). With respect to the focal areas of this research - the governance of sponsorship relationships and creation of value - the results of this case study have highlighted the 
interdependencies of formal and informal governance mechanisms. The findings are relevant to the sport management field, for both sponsoring companies and sport (or event) properties.

Farrelly et al. (2008, p. 60), have suggested that "despite the potential for major sponsorship relationships to function as co-marketing alliances, this type of relationship is still in its infancy". This study supports that claim. Whilst the potential exists for sport sponsorship relationships to be governed as strategic alliances, a number of processes and mechanisms need to be taken into account as the sport industry matures. As Bell et al. (2006) have argued, the majority of alliance studies collect data from only one partner and usually from only one respondent, and thus fail to address the dyadic nature and multiple levels of engagement of interorganisational relationships. By contrast, this study provided a dyadic, in-depth qualitative investigation, and thus offers new data in what have been research areas previously lacking attention.

This study highlights that as well as receiving financial benefits and brand associations, it is in the interest of the sporting body and sponsors to integrate strategic thinking and planning into their sponsorship relationships. Both partners must adequately understand each other's dynamic expectations and objectives to maintain relations.

Interestingly, while stringent contractual regulations were core, informal processes also played a key role in creating value and mitigating tensions between sponsorship partners. Fostering inter-partner confidence is therefore critical. The results demonstrate that trust is a pivotal construct in sponsorship governance. Although relationship strength is not the only driver of renewal, it is probable that the greater the level of support and relational strength, the more positive the sponsorship appraisal. While economic benefit is undoubtedly critical, relational elements have significant impact on renewal intentions. This means that high staff turnover can 
be potentially detrimental to the alliance, particularly as relational continuity, attachment and social bonds might be lost. Turnover may result in an erosion of corporate knowledge and asset specific know-how. It is recommended that processes, routines and expectations be documented to minimise any loss during role transference. However, in this study it was also found that staff turnover within boundary spanning roles may be necessary in certain situations where relations are strained. Managers on both sides of the alliance should be cognisant of inter-personal relationship strength between their staff and their counterparts within partner organisations. The importance of effective human resource management within the sponsorship industry is therefore very evident.

The findings suggested that there is potential to further increased value for both the NSO and sponsors if a more collaborative model is adopted. Sponsors and sport properties need to be clear about their motivations for involvement, their strategic intent and expectations. The managerial challenge is for two cross-sectoral organisations to coordinate strategic planning and objectives. This research suggests that if an effective and cooperative alliance is developed, relational value is more likely to be optimised for both entities.

As with all research, the findings of this study are bound by certain limitations. The empirical data was collected from a single NSO in an Australian event context. This may limit the broad generalisability of findings to other sport and event contexts. Furthermore, as the topic of sponsorship concerns organisations' marketing information and intellectual property, issues of confidentiality became evident. Access to the various personnel managing the sponsorship relationships was granted, providing valuable firsthand information. However, due to intellectual property protection, access to certain marketing and strategic documents was somewhat limited. 
Thus findings are bound by the data that was made available. Moreover, this research drew strongly on interview data for analysis which by its subjective nature has inherent limitations.

It is concluded that sponsorship alliances are complex B2B relationships in which value is generated by the balance of formal and informal governance mechanisms. A key finding of this study is the importance of communication and transparency of partner expectations. Understanding the variables that generate value and maintain alliance stability is critical for improved sponsorship governance and perhaps overall sponsorship performance. Given the ubiquity of sponsorship and its mounting stake in marketing spend for sponsors and revenue generation for sponsees, effective management becomes ever more critical. 


\section{References}

Alexandris, K., Tsaousi, E. \& James, J. (2007), "Predicting Sponsorship Outcomes from Attitudinal Constructs: The Case of a Professional Basketball Event", Sport Marketing Quarterly, vol. 16, no. 3, pp. 130-139.

Amis, J., Slack, T. \& Berrett, T. (1999), "Sport Sponsorship as Distinctive Competence", European Journal of Marketing, vol. 33, no. 3/4, pp. 250.

Apostolopoulou, A. \& Papadimitriou, D. (2004), "'Welcome Home": Motivations and Objectives of the 2004 Grand National Olympic Sponsors", Sport Marketing Quarterly, vol. 13, no. 4, pp. 180-192.

Basit, T. N. (2003), Manual or electronic? the role of coding in qualitative data analysis. Educational Research, vol. 45, no. 2, pp. 143-154.

Bell, J., den Ouden, B. \& Ziggers, G.W. (2006), "Dynamics of Cooperation: At the Brink of Irrelevance", Journal of Management Studies, vol. 43, no. 7, pp. 1607-1619.

Berkes, P., Nyerges, M. \& Vaczi, J. (2009), "The changing of the sponsorship market: The case of Hungarian professional soccer club sponsors", Sportwissenschaft, vol. 39, no. 1, pp. 3544.

Chadwick, S. \& Thwaites, D. (2005), "Managing Sport Sponsorship Programs: Lessons from a Critical Assessment of English Soccer", Journal of Advertising Research, vol. 45, no. 3, pp. 328-338.

Choi, J.A., Stotlar, D.K. \& Park, S.R. (2006), Visual Ethnography of On-site Sport Sponsorship Activation: LG Action Sports Championship, Fitness Information Technology, Inc.

Cornwell, T.B. (2008), "State of the Art and Science in Sponsorship-Linked Marketing", Journal of Advertising, vol. 37, no. 3, pp. 41-55.

Cornwell, T.B. \& Maignan, I. (1998), "An International Review of Sponsorship Research", Journal of Advertising, vol. 27, no. 1, pp. 1-21.

Cornwell, T.B., Roy, D.P. \& Steinard, E.A.,II (2001), "Exploring managers' perceptions of the impact of sponsorship on brand equity", Journal of Advertising, vol. 30, no. 2, pp. 41-51.

Cousens, L., Babiak, K. \& Bradish, C.L. (2006), "Beyond sponsorship: Re-framing corporatesport relationships". Sport Management Review, vol. 9, no. 1, pp. 1-23.

Das, T.K. \& Teng, B.S. (2001), "Trust, Control, and Risk in Strategic Alliances: An Integrated Framework", Organization Studies, vol. 22, no. 2, pp. 251-283. 
Davies, J., Daellenbach, K. \& Ashill, N.J. (2008), "Value in a Multiple Perspective View of Sports Sponsorship", International Journal of Sport Management and Marketing, vol. 3, no. 3, pp. 184-200.

Denzin, N.K. \& Lincoln, Y.S. (2005), The SAGE Handbook of Qualitative Research, SAGE Publications, Thousand Oaks.

Dolphin, R. (2003), "Sponsorship: Perspectives on its strategic role", Corporate Communications, vol. 8, no. 3, pp. 173-186.

Duncan, T. (2002), IMC: Using Advertising and Promotion to Build Brands, McGraw-Hill Irwin, Boston.

Dyer, J.H. \& Singh, H. (1998), "The relational view: Cooperative strategy and sources of interorganizational competitive advantage", The Academy of Management Review, vol. 23, no. 4 , pp. 660-679.

Farrelly, F. (2010), "Not Playing the Game: Why Sport Sponsorship Relationships Break Down", Journal of Sport Management, vol. 24, no. 3, pp. 319-337.

Farrelly, F. \& Quester, P. (2005a), "Examining important relationship quality constructs of the focal sponsorship exchange", Industrial Marketing Management, vol. 34, no. 3, pp. 211219.

Farrelly, F. \& Quester, P. (2005b), "Investigating large-scale sponsorship relationships as comarketing alliances", Business Horizons, vol. 48, no. 1, pp. 55-62.

Farrelly, F., Quester, P. \& Burton, R. (1997), "Integrating sports sponsorship into the corporate marketing function: an international comparative study". International Marketing Review, vol. 14, pp. 170-182.

Farrelly, F., Quester, P. \& Burton, R. (2006), "Changes in sponsorship value: Competencies and capabilities of successful sponsorship relationships", Industrial Marketing Management, vol. 35, no. 8, pp. 1016-1026.

Farrelly, F., Quester, P. \& Clulow, V. (2008), "Exploring Market Orientation and Satisfaction of Partners in the Sponsorship Relationship", Australasian Marketing Journal, vol. 16, no. 2, pp. 51-66.

Farrelly, F., Quester, P. \& Mavondo, F. (2003), "Collaborative Communication in Sponsor Relations", Corporate Communications: An International Journal, vol. 8, no. 2, pp. 128138.

Hanson, D., Dowling, P.J., Hitt, M.A., Ireland, R.D. \& Hoskinsson, R.E. (2005), Strategic Management: Competitiveness and Globalisation, 2nd edn, Thomson, Melbourne. 
Hartland, T., Skinner, H. \& Griffiths, A. (2005), "Tries and conversions: are sports sponsors pursuing the right objectives?", International Journal of Sports Marketing \& Sponsorship, vol. 6 , no. 3 , pp. $164-173$.

Henseler, J., Wilson, B. \& de Vreede, D. (2009), "Can sponsorships be harmful for events? Investigating the transfer of associations from sponsors to events", International Journal of Sports Marketing \& Sponsorship, vol. 10, no. 3, pp. 244-251.

International Event Group (2013), "2013 Sponsorship outlook: Spending increase in doubleedged sword". available at: http://www.sponsorship.com/IEGSR/2013/01/07/2013Sponsorship-Outlook--Spending-Increase-Is-Dou.aspx. (accessed 1 February 2013).

International Olympic Committee (2012), "Olympic Marketing Fact File". available at: http://www.olympic.org/Documents/IOC_Marketing/OLYMPIC-MARKETING-FACTFILE-2012.pdf. (accessed 20 September 2013).

Ireland, R.D., Hitt, M.A. \& Vaidyanath, D. (2002), "Alliance Management as a Source of Competitive Advantage", Journal of Management, vol. 28, no. 3, pp. 413-446.

Kahuni, A.T., Rowley, J. \& Binsardi, A. (2009), "Guilty by association: image 'spill-over' in corporate co-branding", Corporate Reputation Review, vol. 12, no. 1, pp. 52-63.

Kale, P. \& Singh, H. (2007), "Building Firm Capabilities Through Learning: The Role of the Alliance Learning Process in Alliance Capability and Firm-level Alliance Success", Strategic Management Journal, vol. 28, no. 10, pp. 981-1000.

Lagae, W. (2005), Sport Sponsorship and Marketing Communications: A European Perspective, Financial Times Prentice Hall, New Jersey.

Mandal, P., Love, P.E.D. \& Irani, Z. (2003), "Pre-alliance Planning: Development of an Information System Infrastructure to Support Strategic Alliance Activities", Management Decision, vol. 41, no. 2, pp. 132-140.

Meenaghan, T. (1998), "Current developments \& future directions in sponsorship", International Journal of Advertising, vol. 17, no. 1, pp. 3-28.

Meenaghan, T. \& Shipley, D. (1999), "Media Effect in Commercial Sponsorship", European Journal of Marketing, vol. 33, no. 3/4, pp. 328-348.

Miles, M.B. \& Huberman, A.M. (1994), An Expanded Sourcebook: Qualitative Data Analysis. $2^{\text {nd }}$ ed. Thousand Oaks: Sage Publications.

Motion, J., Leitch, S. \& Brodie, R.J. (2003), "Equity in corporate co-branding: The case of adidas and the All Blacks", European Journal of Marketing, vol. 37, no. 7/8, pp. 1080-1094. 
Neuman, W. L. (2003), Social research methods: Qualitative and quantitative approaches (5th ed.). Boston, Massachusetts: Allyn and Bacon.

Nufer, G. \& Bühler, A. (2010), "Establishing and maintaining win-win relationships in the sports sponsorship business", Journal of Sponsorship, vol. 3, no. 2, pp. 157-168.

National Sport Organisation (2012), NSO's website. (accessed: 1 May 2012).

Olkkonen, R., Tikkanen, H. \& Alajoutsijarvi, K. (2000), "Sponsorship as relationships and networks: implications for research", Corporate Communications: An International Journal, vol. 5, no. 1, pp. 12-19.

Olkkonen, R. \& Tuominen, P. (2008), "Fading Configurations in Inter-Organizational Relationships: a Case Study in the Context of Cultural Sponsorship", vol. 23, no. 3, pp. 203212.

Renard, N. \& Sitz, L. (2011), "Maximising sponsorship opportunities: a brand model approach", Journal of Product and Brand Management, vol. 20, no. 2, pp. 121-129.

Ryan, A. \& Fahy, J. (2003), "A Relationship Marketing Perspective on the Sponsorship of the Arts in Ireland: a Galway Arts Festival - Nortel Networks Case Study", Irish Marketing Review, vol. 16, no. 1, pp. 31-42.

Stotlar, D.K. (2004), "Sponsorship Evaluation: Moving from Theory to Practice", Sport Marketing Quarterly, vol. 13, no. 1, pp. 61-64.

Urriolagoitia, L. \& Planellas, M. (2007), "Sponsorship relationships as strategic alliances: A life cycle model approach", Business Horizons, vol. 50, no. 2, pp. 157-166.

Walliser, B. (2003), "An international review of sponsorship research: Extension and Update", International Journal of Advertising, vol. 22, no. 1, pp. 5-40.

Westberg, K., Stavros, C. \& Wilson, B. (2011), "The impact of degenerative episodes on the sponsorship B2B relationship: Implications for brand management", Industrial Marketing Management, vol. 40, no. 4, pp. 603-611. 